\title{
Forecasting energy consumption using ensemble ARIMA-ANFIS hybrid algorithm
}

\author{
Sasan Barak*1, S.Saeedeh Sadegh ${ }^{2}$ \\ 1. Faculty of Economics, Technical University of Ostrava, Ostrava, Czech Republic \\ 2. Department of Industrial Engineering, Tarbiat Modares University, Tehran, Iran
}

\section{Abstract}

Energy consumption is on the rise in developing economies. In order to improve present and future energy supplies, forecasting energy demands is essential. However, lack of accurate and comprehensive data set to predict the future demand is one of big problems in these countries. Therefore, using ensemble hybrid forecasting models which can deal with shortage of data set could be a suitable solution. In this paper, the annual energy consumption in Iran is forecasted using 3 patterns of ARIMA-ANFIS model. In the first pattern, ARIMA (Auto Regressive Integrated Moving Average) model is implemented on 4 input features, where its nonlinear residuals are forecasted by 6 different ANFIS (Adaptive Neuro Fuzzy Inference System) structure including grid partitioning, sub clustering, and fuzzy c means clustering (each with 2 training algorithms). In the second pattern, the forecasting of ARIMA in addition to 4 input features are assumed as input variables for ANFIS prediction. Therefore, four mentioned inputs beside ARIMA's output are used in energy prediction with 6 different ANFIS structures. In the third pattern, due to dealing with data insufficiency, the second pattern is applied with AdaBoost (Adaptive Boosting) data diversification model and a novel ensemble methodology is presented.

The results indicate that proposed hybrid patterns improve the accuracy of single ARIMA and ANFIS models in forecasting energy consumption, though third pattern, used diversification model, acts better than others and model's MSE criterion was decreased to $0.026 \%$ from $0.058 \%$ of second hybrid pattern. Finally, a comprehensive comparison between other hybrid prediction models is done.

Key words: Energy forecasting; ARIMA; ANFIS; AdaBoost; Ensemble algorithm 


\section{Introduction}

Energy is vital important for development of every country from the social, economic and environmental perspective. It has magnificent effect on industrial and agricultural products, health, sanitary, population, education and human life quality [1].

As energy is a crucial input to industrial part of country, energy demand increases along the industrial function increase. Rapid changes in industry and economy strongly affect energy consumption. Therefore, energy consumption is an important economical index that represents economic development of a city or a country [2]. According to the international energy agent report, there should be many transformations in amount and type of future energy consumption (year 2030). As over the past decade global energy consumption has increased rapidly because of population and economic growth [3, 4]. According to wide growth of energy consumption in the last decade, energy demand management is very important for achieving economic success, environment preservation and suitable planning for existing resources that result in self-sufficiency and economic development. Therefore, various techniques have been used for energy demand management to forecast future energy demands accurately [4]. However, energy forecasting is difficult, because it is affected by rapid development of economy, technology, government decisions and other factors [5]. As far as energy prediction is concerned, especially in developing countries like Iran, lack of data are a critical problem in forecasting. Moreover, missing values and lack of a standard and precise system for data collection raised other issues in such countries [6]. This study proposes a diversified hybrid ARIMA (Auto Regressive Integrated Moving Average)-ANFIS (Adaptive Neuro Fuzzy Inference System) model to deal with such problems in energy consumption.

The contribution of the paper is summarized as follow:

- Developing a hybrid ARIMA-ANFIS algorithm based on three different patterns

- Using diversification method to deal with data insufficiency

- Finally, comparing all patterns with different prediction models

This paper is organized as follows. A comprehensive literature for energy forecasting models such as ARIMA, fuzzy and ANFIS models as well as Ensemble models are reviewed in the second section. In the third section details of ARIMA, ANFIS and AdaBoost (Adaptive Boosting) models are described and our proposed algorithms with 3 patterns are explained in 
the fourth section. In the fifth section, the proposed models have been evaluated using energy consumption data from Iran. Finally, conclusions are given in the last section.

\section{Literature review}

Increasing global energy demand requires intelligent forecasting algorithms and models. Suganthi and Samuel [4] have surveyed many different models in the field of energy forecasting and introduced two types of models including: 1- Traditional forecasting models such as: time series, regression, econometrics models, and ARIMA, 2- Soft computing models such as: fuzzy logic, genetic algorithm, neural network, support vector regression models for forecasting national and regional energy demand.

Time series models are the simplest models for trend analysis in energy forecasting. Some time series approaches like traditional statistical models including: moving average, exponential smoothing and ARIMA are linear forecasting methods [7].

ARIMA model is one of the most popular time series models and has been broadly used [4, 7]. Pappas, Ekonomou [8] proposed ARIMA model for forecasting Greek electricity consumption and compared the proposed model with three analytical time-series models. Results showed that ARIMA model is more efficient than the other time-series models.

From the other point of view, statistical forecasting methods usually require normal data, while large data sets are trendy or seasonal data pattern are often inadequate or noisy $[2,9$, 10]. ARIMA models are linear but real time series rarely has linear structure.

Energy demand is forecasted based on economic and non-economic indexes. The nonlinearity of these indexes and energy demand have led to a search in the field of artificial intelligence approaches such as neural network and fuzzy models [11]. These methods are used because of high flexibility and power of forecasting, estimating and overcoming with noisy data [12].

Pao [13] forecasted Taiwan energy consumption by neural networks and linear models. Neural network has functioned better than the linear models.

But depending on situation, accuracy of ANN methods decrease because of several reasons. Forecasting accuracy of ANN depends on learning data set and their adequacy. Moreover ANN methods sometimes get stuck in local minimum, so choosing proper data set, is too critical in neural network models and these models get good results only when the number of data is high [14]. 
Fuzzy models have good results in varying situations with inadequate data. Recently, fuzzy logic has been widely used to deal with high level of uncertainty issues $[15,16]$. Accuracy of energy forecasting is usually impressed by data uncertainty and interdependency between model's variables. These relations are eliminated by classification of fuzzy model [17]. Mamlook, Badran [18] forecasted short term electricity consumption of Jordan by fuzzy model and found that fuzzy model performed much better than the usual statistical forecasting models.

Yet, probabilistic consumption pattern cannot be correctly forecasted just by fuzzy based or time- series models. Azadeh, Asadzadeh [6] proposed fuzzy-regression hybrid model to improve estimation and forecasting of energy consumption, with use of small set of (inadequate) data, population and GDP as inputs. They used annual data from Iran and some other countries from 1995 to 2005 and the results showed the superiority of proposed hybrid model compared to single models. The application of fuzzy models in energy is reviewed by [19]. The review indicates that fuzzy based models in energy field provide realistic estimates.

\subsection{ANFIS}

ANFIS (Adaptive Neuro Fuzzy Inference System) model is one of the most popular artificial intelligent models that have got advantages of both neural network and fuzzy model. The first application of ANFIS in time-series prediction is the Jang's work [20]. In ANFIS, the relations between variables are shown by fuzzy If-Then rules. Therefore it can interpret the obtained results, which is not possible with the structures such as neural network [21]. It is also one of the best models in estimation function among other neuro-fuzzy models[22].

Ying and Pan [23] applied ANFIS model to forecast annual regional electricity load in Taiwan with data of years from 1981 to 2000. According to MAPE criteria and statistical results, ANFIS model was found to perform better than regression, neural network, support vector machines, genetic model and fuzzy hybrid systems. Efendigil, Önüt [10] compared neural network and ANFIS model for forecasting demand with incomplete data. Results showed that ANFIS could be used in demand forecasting with limited data. Akdemir and Çetinkaya [24] proposed an ANFIS model to forecast the annual energy demand in Turkey with use of population, income level, peak load and energy demand data for 27 years. In spite of small number of data, good results were obtained. Al-Ghandoor, Samhouri [25] forecasted energy demand in Jordan's transportation, with the use of two models: ANFIS and quadratic exponential smoothing. Annual data from 1985 to 2009 were used to forecast energy demand for years from 2010 to 2030 and results expressed efficiency of ANFIS model in energy 
demand forecasting. Thus, most of the results showed that ANFIS had good results in energy demand modeling and forecasting.

\subsection{ARIMA-ANFIS}

Recently, hybrid ANFIS models have been successfully used. Azadeh, Saberi [26] proposed a hybrid ANFIS model for forecasting monthly electricity demand in Iran and yielded good results compared to time series model, genetic algorithm and neural network. $\mathrm{Li}, \mathrm{Su}$ [27] compared neural network and genetic- ANFIS hybrid model to forecast daily energy demand of a hotel. Results showed good performance of hybrid model, though hybrid model was complicated. $\mathrm{Li}$ and $\mathrm{Hu}$ [28] proposed an ARIMA-fuzzy system model for time series forecasting. First, a Sugeno fuzzy model was applied on input-output data to produce fuzzy rules. Then, ARIMA model was embedded in answer part of fuzzy rules and obtained good results. Babu and Reddy [29] proposed a hybrid model of ARIMA and ANN based on moving-average filter model. Then, using a simulated data set and experimental data sets such as sunspot data, electricity price data, and stock market data, the proposed hybrid ARIMA-ANN model was applied along with individual ARIMA and ANN models and some existing hybrid ARIMA-ANN models. Table 1 shows some features and results of the explained studies:

**Insert Table 1 Here: Review of hybrid energy forecasting implementations **

As can be seen from Table 1, the performance of hybrid ANFIS model in energy forecasting, is so brilliant especially in lack of data and varying situations and more precise results have been achieved after hybridization with other models. Also, using ensemble model as a new concept has improved the result of energy forecasting [40].

\subsection{Ensemble models:}

Recently, studies in machine learning have shown the prediction with a series or ensemble of models is better than a single model and practice of one model improves by hits of other models. An ensemble methodology uses advantages of some predictive models to achieve better results. Ensemble method has two kinds of learning approach: learning without interaction between the learning agents (ensemble learning) and learning with interaction during the learning step (co-learning)[41].

In another point of view, ensemble models classified based on data diversification. Some algorithms of this classification are: $\mathrm{K}$ - fold cross validation, Bagging, Boosting, and Random forests. 
In K-fold cross validation method, training and validation data sets are divided to $\mathrm{K}$ equal parts. One part is considered as validation data and $\mathrm{K}-1$ other parts are considered as training data. This is done in $\mathrm{K}$ times and each time one new part is considered as validation data and others as training set [42]. Boosting and Bagging methods combine weak models and provide better prediction models. Bagging is appropriate for improving tree algorithms while Boosting can be used for many algorithms such as additive models with high-dimensional predictors [43].

Adaptive Boosting (AdaBoost) proposed by Freund and Schapire [44] is an effective ensemble method that enjoys weighted average method for combination of learning algorithms.

Recently, AdaBoost has been successfully used in many fields of study, few of them are: cost-sensitive classification, semi supervised learning, tracking and network intrusion detection [45, 46]. Assaad, Boné [47] predicted future values of time series using neural networks as base learners and AdaBoost ensemble method. Alfaro, García [48] compared the results of AdaBoost and neural network techniques in the field of forecasting by about thirty percent decrease in generalization error, and deduced the priority of AdaBoost method results. Heo and Yang [49] used AdaBoost in bankruptcy forecasting and achieved remarkable results. Taking a step forward, we develop a novel combination of AdaBoost methodology with hybrid ARIMA-ANFIS model to improve the forecasting result of energy consumption prediction.

\section{The background}

\subsection{ARIMA model}

An ARIMA model [ARMA $(p, q)$ ] for $x$ time series that includes $n$ instances is predefined as [50]:

$x_{k}=\sum_{i=1}^{p} A_{i} x_{k-i}+\sum_{j=1}^{q} B_{j} v_{k-j}+v_{k} \quad E\left[v_{k} v_{k}^{T}\right]=R$

where the $m$-dimensional vector $v_{k}$ is uncorrelated random noise, not necessarily Gaussian, with zero-mean and covariance matrix $R, \theta=(p, q)$ is the order of the predictor and $A_{1, \ldots} \ldots A_{p}$ and $B_{1, \ldots}, B_{q}$ are the $m \times m$ coefficient matrices of the multivariate (MV) ARMA model [50]. ARIMA model has three components: 1- auto regressive (AR), 2-integrated average (IA) 3moving average (MA). The structure of ARIMA model consists four steps: 1- model 
identification, 2- parameter estimation, 3- model recognition, 4- model verification and forecasting [28].

In ARIMA $(p, d, q), p$ expresses the number of autoregressive terms, $q$ is the number of lagged forecast errors and $d$ is the number of non-seasonal differences. Random errors $\left(v_{k}\right)$ are assumed to be independent, and to have identical distribution with a constant variance. Based on Box and Jenkins method, when the numbers of series are less than 240, maximum number of lag is equal to the number of observations divided by four [51]. To apply ARIMA model, autocorrelation (ACF) and partial autocorrelation (PACF) functions should be determined. Order of the AR and MA parameters can be determined using the partial autocorrelation graph and the autocorrelation graph of data. Descriptions of steps for creating ARIMA model are as follow:

Model identification: As stationary is essential in ARIMA forecasting model, data should be often stationary. Differencing is usually applied to data to remove trend of data and stabilize the variance [28]. By this way, $d$ parameter is determined. According to PACF and ACF figures, time series and probabilistic models' stationary can be determined.

Parameter estimation: One of probabilistic models is made and model's parameters are estimated, in order to minimize Akaike's Information Criterion (AICC) [52] and Schwarz's Bayesian Information Criterion (BIC) [12, 28, 50].

Diagnostic checking: In this step, the model's accuracy and the model's error stationary are checked [28]. The best model is chosen according to some forecasting error criteria such as root mean square error (RMSE) and mean absolute error (MAE). In Figure 1, the process of choosing the best ARIMA model is shown:

\section{**Insert Figure 1 Here: Pattern of ARIMA model **}

\subsection{ANFIS}

Takagi-Sugeni-Kang is a fuzzy system with crisp functions that is suitable for complex problems. TSK systems are usually used in the shape of a neuro fuzzy system that is called ANFIS. ANFIS is a fuzzy inference system that can be trained by a set of input and output data.

\section{** Insert Figure 2 Here: ANFIS structure $* *$}

The ANFIS structure shown in Figure 2 is a five layer network. The first layer executes a fuzzification process, the second layer executes the fuzzy AND of the antecedent part of the fuzzy rules, the third layer normalizes the membership functions, the fourth layer executes the conclusion part of the fuzzy rules, and the last layer computes the output of the fuzzy 
system by summing up the outputs of the four layers. The feed forward equations of the ANFIS structure with two inputs and two labels for each input shown in Figure 2 are as follows according to 3 type rules:

$$
\begin{aligned}
& W_{i}=\mu_{A_{i}}(x) \times \mu_{B_{i}}(x) \quad i=1,2 \\
& \bar{w}_{i}=\frac{w_{i}}{w_{1}+w_{2}}, \quad i=1,2 \\
& \left\{\begin{array}{l}
f_{1}=p_{1} x+q_{1} y+r_{1} z \\
f_{2}=p_{2} x+q_{2} y+r_{2} z
\end{array} \Rightarrow f=\frac{w_{1} f_{1}+w_{2} f_{2}}{w_{1}+w_{2}}=\bar{w}_{1} f_{1}+\bar{w}_{2} f_{2}\right.
\end{aligned}
$$

where $x$ and $y$ are inputs to node $i, A_{i}$ and $B_{i}$ are linguistic labels for inputs, and $w_{i}$ is the output of layer 3 and $\left\{p_{i}, q_{i}, r_{i}\right\}$ is the parameter set.

There are 3 kinds of function for fuzzy system creation: Genfis1, Genfis2, Genfis3.

Genfis1 makes fuzzy inference system structure by grid partitioning. It makes FIS structure based on constant numbers of membership functions, uses clustered information models the data behavior, in the best way and with the least number of functions. It clusters its rules based on fuzzy quality of data sets [53].

Genfis 2 makes the structure of FIS by subtractive clustering. This method makes a model of data by clustering and a cluster radius should be determined for it. Radius specifies the confinement (limitation) of cluster impact $[1,53]$.

Genfis3 makes the FIS structure by fuzzy clustering with use of C-mean (FCM). FCM begins to work with an initial guess for cluster center. In addition, FCM function assigns a membership degree to each data point and guides data centers to their correct place in data set via updating centers and membership degrees of each data point repeatedly. This method is done with minimizing a goal function that represents the distance of each data point to data center that has been weighted by membership degree of the data point (Eq. 5).

$$
J_{m}=\sum_{i=1}^{N} \sum_{j=1}^{C} U_{i j}^{m}\left\|X_{i}-C_{j}\right\|^{2}, 1 \leq m \leq \infty
$$

where $m$ is a real number greater than 1 and each of $U_{i j}, X_{i}$ and $C_{j}$ shows the degree of membership of $X_{i}$ in the $j$-th cluster, the $i$-th p-dimensional data and the p-dimensional center of the cluster respectively, and $\|*\|$ is any norm that shows the similarity between each measured data and the center. With iterative optimization of the above objective function, fuzzy partitioning is done, by updating membership $U_{i j}$ and cluster centers $C_{j}$ as follow: 


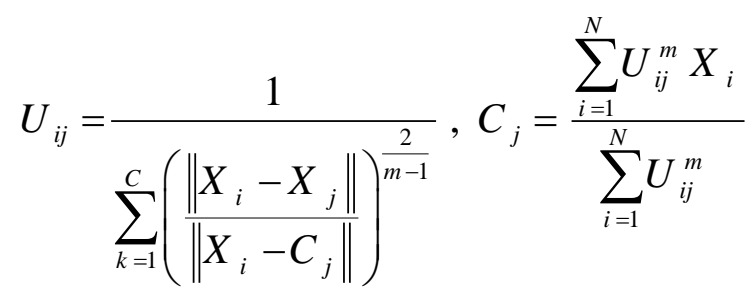

when $\max _{i, j}\left\{\left|U_{i j}^{(K+1)}-U_{i j}^{(K)}\right|\right\} \prec \varepsilon$ is satisfied, iteration will stop, where $\varepsilon$ is a number between 0 and 1 , and $k$ is the step's number of iteration $[1,53]$.

\subsection{AdaBoost}

Ensemble methods are broadly used for classification and regression and their ability has been shown in a wide range of tasks, theoretically and empirically[47].

Boosting uses a series of classifier to learn the model. In each iteration one classifier $\left(m_{i}\right)$ is learned and new weights are assigned to data in order to next classifier "pay more attention" to tuples that has been classified wrong. Weight of each classifier's vote is counted according to its accuracy. Finally, votes of classifiers are combined to make the best classifier $\left(m^{*}\right)$ [54].

In AdaBoost as the most popular Boosting algorithm, a series of models are combined and data set are resampled in each model. In this method data are weighted according to their difficulty to be learned [45].

\section{The proposed model}

Both ARIMA and ANFIS models have good performance in linear and nonlinear structures but none of them is comprehensive to be able to forecast various time series structures. Studies show that using dissimilar models improves time series forecasting where data pattern is varying and unstable [7, 19]. The use of ARIMA and soft computing techniques improves precision of energy demand forecasting [4].

Zhang [7] proposed a capable hybrid model that consists of two steps: Step 1 is applying linear model and step 2 is applying non-linear model using linear model's residuals. Finally, both models' forecasting results are summed.

$$
\begin{aligned}
& y_{t}=l_{t}+n_{t} \\
& e_{t}=y_{t}-l_{t}
\end{aligned}
$$


According to (7), it is supposed that data structure $\left(y_{\mathrm{t}}\right)$ contains two parts: Linear part $\left(l_{\mathrm{t}}\right)$ and nonlinear part $\left(n_{\mathrm{t}}\right)$. First, data are forecasted by linear model and have been checked to see if residuals $\left(e_{t}\right)$ have nonlinear pattern. Then, the residuals have been forecasted by a nonlinear model. The model's final forecasting is attained from sum of linear and nonlinear model results. In equation $8, e_{\mathrm{t}}$ is nonlinear residual that is yielded by subtracting actual quantity to linear forecasted quantity.

Extending the previous researches, in our paper, 3 patterns for time series prediction are presented. In the first pattern, data are forecasted by ARIMA model, then its residuals are forecasted with ANFIS model and finally forecasting is attained from sum of ARIMA and ANFIS model.

In the second pattern, the forecasting of ARIMA is used as an input feature to ANFIS model. In other words, the forecasting of ARIMA in addition to other input features are used in ANFIS prediction. Therefore, ARIMA's output as one of ANFIS inputs, can improve ANFIS model's performance. In the third pattern, because of the lack of data, the second pattern is applied with AdaBoost model.

Two training algorithms including back propagation (BP) and least square gradient descent back propagation (Hybrid BP) are implemented in ANFIS model to train parameters of membership functions. Hybrid algorithms for TSK-type of fuzzy logic systems are provided in various studies [55] which is a combination of least square and gradient descent back propagation.

Since ANFIS prediction in this study is examined with 3 kinds of Genfis functions (Grid partitioning, Sub clustering, FCM) with 2 training algorithms, we calculate 6 kinds of ANFIS structures.

Modeling steps are described as follows:

A. By choosing proper quantity for alpha and beta in equation 9, all data are normalized in $[\alpha, \alpha+\beta]$ interval.

$$
\mathrm{x}_{\mathrm{norm}}=\alpha+\beta\left(\frac{\mathrm{x}-\mathrm{x}_{\min }}{\mathrm{x}_{\text {max }}-\mathrm{x}_{\text {min }}}\right)
$$

B. According to pattern and situation of model's residuals, and stationarity or nonstationarity, ARIMA parameters including: AR, MA and $d$ are identified and ARIMA model is applied. Linear parts of data are forecasted and model's error is attained by subtracting actual quantity of forecasted quantity: 
$e_{t}=y_{\mathrm{t}}-l_{\mathrm{t}}$

where $y_{t}$ is actual quantity and $l_{t}$ is linear part.

**Insert Figure 3 Here: Proposed hybrid ARIMA-ANFIS model **

In the first proposed pattern, steps are as follows (see the right side of Figure 3):

1.1. Since residuals of ARIMA have nonlinear structures, ANFIS model is used to forecast ARIMA residuals. So residuals are divided into train and test sets, then 6 different ANFIS models are trained and tested. Error reduction is used as criteria for choosing proper model. The formula for this model is shown in equation 11:

) 11(

$$
y_{k}=l_{k}+n_{k}=\sum_{i=1}^{p} a_{i} l_{k-i}+\sum_{j=1}^{q} b_{j} v_{k-j}+\left(w_{1} f_{1}+w_{2} f_{2}\right) /\left(w_{1}+w_{2}\right)
$$

Equation 11 considers both linear and nonlinear forecasting parts in forecasting and illustrates final forecasting values by sum of ARIMA and ANFIS results. Model's error is computed by mean square error (MSE) criteria:

$M S E=\frac{1}{n} \sum_{i=1}^{n}\left(q_{i}^{c}-q_{i}^{m}\right)^{2}$

where $q_{i}^{c}$ is forecasted value, $\mathrm{q}_{i}^{m}$ is real value, and $n$ is the number of data.

$M S E$ is used as criteria for choosing proper model.

1.2. After obtaining the results of 6 ANFIS models, outputs are post processed, returned to initial scale and presented as hybrid model's results.

In the second pattern, steps "a" and "b" are similar to the first pattern model (see the left side of Figure 3). Steps 2-1 to 2-3 are as follow:

2.1. The ARIMA model's prediction is used as one of ANFIS inputs. Therefore, linear forecasting results are added to other ANFIS inputs and energy consumption is used as model's output. For example, where ARIMA output $\left(l_{t}\right)$ and the other inputs $(m)$ are considered as ANFIS inputs the model's formula can be expressed as follow:

$$
\begin{aligned}
& f=\left(w_{1} f_{1}+w_{2} f_{2}\right) /\left(w_{1}+w_{2}\right)= \\
& \frac{\mu_{a_{1}}\left(l_{\mathrm{t}}\right) \times \mu_{b_{1}}\left(l_{\mathrm{t}}\right) \times\left(p_{1} l_{\mathrm{t}}+q_{1} m+\mathrm{r}_{1}\right)+\mu_{a_{2}}\left(l_{\mathrm{t}}\right) \times \mu_{b_{2}}\left(l_{\mathrm{t}}\right) \times\left(p_{2} l_{t}+q_{2} m+\mathrm{r}_{2}\right)}{\mu_{a_{1}}\left(l_{\mathrm{t}}\right) \times \mu_{b_{1}}\left(l_{\mathrm{t}}\right)+\mu_{a_{2}}\left(l_{\mathrm{t}}\right) \times \mu_{b_{2}}\left(l_{\mathrm{t}}\right)}
\end{aligned}
$$

where $l_{t}$ is the output of ARIMA model. 
2.2. In this step, data is divided into train and test sets, then data are analyzed with 6 structures of ANFIS models. The best hybrid model is specified with respect to test criteria and used for forecasting energy consumption.

2.3. After obtaining ANFIS results, outputs are post processed, returned to initial scale and presented as hybrid model's results.

As far as energy prediction is concerned, especially in developing countries like Iran, lack of data are a big problem in forecasting. Therefore, in the third pattern, for improving testing accuracy of model and encountering with lack of data AdaBoost method is applied to increase data variation. In the last pattern of this study, AdaBoost method was implemented based on figure 4 .

\section{**Insert Figure 4 Here: AdaBoost method **}

The mathematical model of presented AdaBoost is as follows:

Input: Initial training set composed of $\mathrm{n}$ examples, denoted as

$$
s_{n}=\left\{\left(x_{1}, y_{1}\right),\left(x_{2}, y_{2}\right), \ldots,\left(x_{n}, y_{n}\right)\right\}
$$

Initialize: $w_{1}^{i}=1 / \mathrm{n}$, i.e. $w_{1}=\left\{w_{1}^{1}, w_{1}^{2}, \ldots, w_{1}^{n}\right\}=\{1 / \mathrm{n}, 1 / \mathrm{n}, \ldots, 1 / \mathrm{n}\}$

$$
\text { for } \mathrm{t}=1,2, \ldots, \mathrm{T}
$$

1. Take $R_{t}$ samples randomly from $S_{n}$ using distribution $w_{t}$

2. Build a classifier $f_{t}$ using $R_{t}$ as the training set

3. Compute: $\mathrm{E}_{\mathrm{t}}=\mathrm{MSE}$ of $f_{t}$ and $\alpha_{\mathrm{t}}=0.5 \ln \left(\frac{1-\mathrm{E}_{\mathrm{t}}}{\mathrm{E}_{\mathrm{t}}}\right)$

4. Update the weight: $\mathrm{w}_{\mathrm{t}+1}^{\mathrm{i}}=\operatorname{normalize}\left(\mathrm{w}_{\mathrm{t}}^{\mathrm{i}} * \exp \left(-\alpha_{\mathrm{t}}\right)\right)$

Output: The ensemble prediction: $\mathrm{F}=\frac{\sum_{t=1}^{T} f_{t}}{T}$ and whole Error $=\frac{\sum_{t=1}^{T} E_{t}}{T}$

where $s_{n}=\left\{\left(x_{1}, y_{1}\right),\left(x_{2}, y_{2}\right), \ldots,\left(x_{n}, y_{n}\right)\right\}$ represents the set of training samples, $\mathrm{T}$ is the number of iteration, $w_{t}=\left\{w_{t}^{1}, w_{t}^{2}, \ldots, w_{t}^{n}\right\}$ shows weight distribution over sample set that is $1 / \mathrm{n}$ in the first iteration and it will be updated in each iteration. Weights for hard samples which classified wrong classifier $\left(f_{t}\right)$ will increase in the next iteration. $E_{t}$ represents MSE of $f_{t}$.

C. Finally, results of 3 patterns have been compared and the best pattern has been chosen. 


\section{Application and results}

\subsection{Data set and experiments}

According to estimations, industrial energy consumption in developing countries is about $45 \%$ to $50 \%$ of total commercial energy consumption [4]. Iran requires broadly investment in energy field, having respectively second and fifth rate in gas and oil reservoirs in the world [56]. On the other hand, in developing countries like Iran, lack of data is a problem in forecasting [6]. Because of this, it seems essential to achieve a proper and accurate model for forecasting future energy consumption in Iran. Therefore, the proposed ensemble based ARIMA-ANFIS hybrid models were used in forecasting.

It is clear from the related literature [57-59] that usually 4 independent variables, including: population, gross domestic production, import and export, are used as inputs to the models in energy consumption forecasting. It seems that these four factors have the most impact on energy consumption in every country. Thus, in this study, annual energy consumption, population, GDP, export and import data from 1967 to 2012, were used for modeling energy consumption. Data were collected from statistics center of Iran. Initial data were normalized according to equation 9 to become stationary. In this study, alpha and beta values are zero and one, respectively. In the next section, various models introduced in previous sections are implemented and results are analyzed.

\subsection{ARIMA}

In this section, ARIMA model is identified for forecasting Iran energy consumption and details of ARIMA model implementation is expressed. Results of ARIMA model are achieved using Eviews software.

Identification step: Ascending pattern is seen in correlation figure of data that shows nonstationary of data (Figure 5).

**Insert Figure 5 Here: Auto correlation and partial auto correlation in data before lagging** Therefore with making one difference on data, 1 was assigned to $d$ parameter.

Pattern estimation step: According to data correlation with 1 lag, 1 and 2 are considered as estimated values for AR parameter and 1, 2, 3 are calculated as estimated values for MA parameter. So various models are compared and two best models are: $[1,1,2]$ and $[2,1,1]$. Model recognition: Model's equations are written considering determined characteristics and models are compared according to the Akaike [52] and Schwarz (BIC) criterions. AIC and BIC criterions for models are compared in table 2, and $[1,1,2]$ model with $\mathrm{AR}=1$ and $\mathrm{MA}=2$ is chosen as the best ARIMA model because of low value for AIC and BIC criterions. 


\section{**Insert Table 2 Here: AIC and BIC criterions comparison **}

Model verification: Residuals` figure is examined and if it is stationary, model recognition is correct. Results show the auto and partial autocorrelations for residuals of $[1,1,2]$ and $[2,1$, 1] models are stationary, however, [1, 1,2] model's residuals have less and smoother correlation and auto correlation and it has better performance (see Figure 6).

** Insert Figures 6 Here: Autocorrelation and partial autocorrelation for residuals of $[1,1,2]$ **

**Insert Table 3 Here: Error criteria results of sample ARIMA model **

Forecasting step: $[1,1,2]$ model is chosen for forecasting because of its low RMSE and MAE criterions (See Table 3).

\subsection{ARIMA-ANFIS patterns}

In this section, three different ARIMA-ANFIS hybrid patterns are employed according to the mentioned methods.

In the first pattern, after forecasting energy consumption with ARIMA (step B), its errors which is difference between actual and forecasted consumptions are calculated and forecasted using population, GDP, import, and export as inputs. Errors have nonlinear pattern as can see in figure 7. Then, combination of ARIMA model and proper nonlinear ANFIS model is implemented.

\section{**Insert Figure 7 Here: ARIMA model forecasting residuals figure **}

Data were divided into train and test sets. $70 \%$ of data is used as train and $30 \%$ as test set and MSE criterion is used to examine model's efficiency. Six different ANFIS structure models have been made by combining 2 optimization algorithms (BP and hybrid BP) and 3 ANFIS types, as mentioned in section 4. Table 4 contains MSE results for various ANFIS models in test period.

\section{**Insert Figure 8 here: Outputs and errors of the best hybrid pattern 1 ** \\ **Insert Table 4 Here: MSE results of hybrid pattern1**}

It is clear from the table 4 that sub clustering ANFIS structure with hybrid BP optimization method has the least test error. Train and test result of the best hybrid pattern 1 is shown in figure 8. As can be seen from figure 8, learning errors are concurrent around zero and close to normal graph. Testing errors are also close to zero.

At second pattern after ARIMA model implementation, ARIMA output that expresses linear forecasting part of time series is used as one of the ANFIS inputs (step 2-1). Because ARIMA is very effective for forecasting linear part of data, using ARIMA results in ANFIS improves time series' total forecasting pattern. Thus ANFIS model inputs are: population, GDP, import 
and export and the other input which is ARIMA forecasting result. With examining different data divisions, using $80 \%$ of data for training and $20 \%$ for testing obtained the best results in this sample (step 2-2). In Table 5, MSE criterion results of various ANFIS structure for second hybrid pattern (hybrid pattern 2) are calculated.

$$
\text { **Insert Table } 5 \text { Here: MSE results of hybrid pattern } 2 * *
$$

Base on table 5, FCM ANFIS structure with BP training algorithm has the least test error. As shown in Figure 9, FCM type of ANFIS with BP has training errors around zero and close to normal graph. Testing errors are also close to zero that is another reason for efficiency of the model in forecasting energy consumption.

**Insert Figures 9 here: Outputs and errors of the best hybrid pattern $2 * *$

Fuzzy rules that are obtained from ANFIS model of hybrid pattern 2 are shown in Table 6. Here, in1 to in5 are the model inputs which are 1.the ARIMA output, 2.population, 3.GDP, 4.import, and 5.export. Out1 is energy consumption that is output of model. As can be seen, the number of rules is decreased regarding to hybrid pattern which shows stationarity of the model and less over training and over fitting. According to the [60], the dense structure of models bring about a low level of over fitting and cause a robust prediction.

**Insert Table 6 Here: Fuzzy rules obtained from hybrid pattern $2 * *$

At the third hybrid pattern, AdaBoost method is mixed with hybrid pattern 2, and proper results were obtained. Results of 10 iterations are shown in figures 10-14.

**Insert Figures 10-14 Here: MSE criterion figures of test data of hybrid pattern 3 based on

$$
\begin{gathered}
\text { diversification method } * * \\
* * \text { Insert Table } 7 \text { Here: MSE results of hybrid pattern } 3 * * \\
* * \text { Insert Table } 8 \text { Here: Results of the best practice of hybrid pattern 1, } 2 \text { and } 3 * *
\end{gathered}
$$

As it is shown in tables $7 \& 8$, hybrid pattern 3 improved MSE criterion and had the best performance between 3 kinds of proposed hybrid pattern. So, it can be used as a proper model for energy consumption in Iran. The proposed hybrid patterns are compared with ANN, single ARIMA, ANFIS, and 3 best known literature studies in Table 9. It is inferred from the table 8 that ANFIS has dominant results regarding ANN algorithms, so much as, single ANFIS model has better performance than Zhang [7] hybrid model. In the other cases, the hybrid models perform better than the single models. Among the hybrid models, the results illustrate that the hybrid pattern 1 over trained. Therefore, the training results has the best result amongst all methods while its testing results gets at least results amongst all hybrid models and just get better results than single models. We also compared the results with [61] 
and [62] works; however, the third hybrid pattern has the best accuracy in forecasting energy consumption between all methods.

\section{** Insert Table 9 Here: Comparison results **}

Until this part of paper, fuzzy inference systems (FIS) and adaptive neuro-fuzzy inference systems (ANFIS) have been designed using classic views such as gradient descend and back propagation. One of improvement and optimization methods in proposed model is optimization of model parameters in learning step. So using Meta-heuristic algorithms in Takagi-Sugeno fuzzy systems may improve parameter selection in learning steps and finally improve the results.

In this part, we tried to study impact of genetic algorithm (GA) and particle swarm optimization (PSO), as two famous Meta heuristic methods, on optimization of learning parameters and MSE criteria. Pattern of genetic algorithm has shown in figure 15.

**Insert Figures 15 Here: ANFIS optimization using GA**

In this pattern, optimal values of parameters are considered as coefficients of parameters value in basic system. These coefficients are estimated using GA or PSO or other Metaheuristic algorithms to minimize error criteria or MSE.

According to this framework, results of Optimized ANFIS with GA and PSO are shown in Error! Reference source not found.. As it is shown, MSE and RMSE criteria have been improved in both Meta-heuristic algorithms and the overall average of 5 iterations obtain better results than non-optimized single ANFIS model. However, the proposed ensemble algorithm (hybrid pattern 3 ) is outperformed than both optimized algorithms.

**Insert Table 10 Here: Results of optimized ANFIS using GA and PSO **

\section{Conclusion}

According to the various applied models in this study, it can be assumed that using special linear and nonlinear models can present desirable results with high correctness, especially when both models have good forecasting strength. Because ARIMA model can forecast linear part of data well also using an effective nonlinear model like ANFIS, increases forecasting efficiency.

Comparing suggested models, we can conclude while hybrid patterns have more accuracy and strength than each model separately, nevertheless using ensemble methods in forecasting improves performance of model. According to results, third hybrid pattern which uses 
AdaBoost method with Genfis3 ANFIS structure and back propagation training algorithm has better results and model's MSE criterion was decreased to $0.026 \%$ from $0.058 \%$ of second hybrid pattern. Therefore, this model can successfully be used for energy consumption in Iran.

What makes our study differs from other is using 2 novel patterns (pattern 2 and 3 ) in time series prediction. Because of the fact that lack of data in forecasting field is one of the most critical issues, the third pattern can be widely used in time series prediction models while the data is inadequate.

In future studies, new diversification methods as well as using other prediction model such as Support Vector Machines can be used to improve results. Also, finding the best values of AdaBoost method parameters, with a powerful method like genetic algorithm can make remarkable results. Moreover, each of inputs can be forecasted by ARIMA model and results used as the input of hybrid models.

\section{Acknowledgment}

The research was supported through the Czech Science Foundation (GACR) under project 15-23699S and through SP2016/11, a SGS research project of VSB-TU Ostrava, and furthermore by the European Social Fund in the framework of CZ.1.07/2.3.00/20.0296.

\section{References:}

[1] Abbasimehr H, Setak M, Tarokh M. A neuro-fuzzy classifier for customer churn prediction. Int J Comput Appl. 2011;19:35-41.

[2] Lee Y-S, Tong L-I. Forecasting energy consumption using a grey model improved by incorporating genetic programming. Energy conversion and Management. 2011;52:147-52.

[3] Ekonomou L. Greek long-term energy consumption prediction using artificial neural networks. Energy. 2010;35:512-7.

[4] Suganthi L, Samuel AA. Energy models for demand forecasting-A review. Renewable and Sustainable Energy Reviews. 2012;16:1223-40.

[5] Yu S, Wei Y-M, Wang K. A PSO-GA optimal model to estimate primary energy demand of China. Energy Policy. 2012;42:329-40.

[6] Azadeh A, Asadzadeh S, Saberi M, Nadimi V, Tajvidi A, Sheikalishahi M. A neuro-fuzzy-stochastic frontier analysis approach for long-term natural gas consumption forecasting and behavior analysis: the cases of Bahrain, Saudi Arabia, Syria, and UAE. Applied Energy. 2011;88:3850-9.

[7] Zhang GP. Time series forecasting using a hybrid ARIMA and neural network model. Neurocomputing. 2003;50:159-75.

[8] Pappas SS, Ekonomou L, Karamousantas DC, Chatzarakis G, Katsikas S, Liatsis P. Electricity demand loads modeling using AutoRegressive Moving Average (ARMA) models. Energy. 2008;33:1353-60.

[9] Lee Y-S, Tong L-I. Forecasting nonlinear time series of energy consumption using a hybrid dynamic model. Applied Energy. 2012;94:251-6.

[10] Efendigil T, Önüt S, Kahraman C. A decision support system for demand forecasting with artificial neural networks and neuro-fuzzy models: A comparative analysis. Expert Systems with Applications. 2009;36:6697-707.

[11] Azadeh A, Ghaderi S, Sohrabkhani S. A simulated-based neural network algorithm for forecasting electrical energy consumption in Iran. Energy Policy. 2008;36:2637-44.

[12] Azadeh A, Saberi M, Seraj O. An integrated fuzzy regression algorithm for energy consumption estimation with nonstationary data: a case study of Iran. Energy. 2010;35:2351-66.

[13] Pao H-T. Comparing linear and nonlinear forecasts for Taiwan's electricity consumption. Energy. 2006;31:2129-41.

[14] Padmakumari K, Mohandas K, Thiruvengadam S. Long term distribution demand forecasting using neuro fuzzy computations. International Journal of Electrical Power \& Energy Systems. 1999;21:315-22. 
[15] Acaroglu O, Ozdemir L, Asbury B. A fuzzy logic model to predict specific energy requirement for TBM performance prediction. Tunnelling and Underground Space Technology. 2008;23:600-8.

[16] Ciabattoni L, Grisostomi M, Ippoliti G, Longhi S. Fuzzy logic home energy consumption modeling for residential photovoltaic plant sizing in the new Italian scenario. Energy. 2014;74:359-67.

[17] Hao J, Liu D, Li Z, Chen Z, Kong L. Power system load forecasting based on fuzzy clustering and gray target theory. Energy Procedia. 2012;16:1852-9.

[18] Mamlook R, Badran O, Abdulhadi E. A fuzzy inference model for short-term load forecasting. Energy Policy. 2009;37:1239-48.

[19] Suganthi L, Iniyan S, Samuel AA. Applications of fuzzy logic in renewable energy systems - A review. Renewable and Sustainable Energy Reviews. 2015;48:585-607.

[20] Jang J-S. ANFIS: adaptive-network-based fuzzy inference system. Systems, Man and Cybernetics, IEEE Transactions on. 1993;23:665-85.

[21] Alizadeh M, Jolai F, Aminnayeri M, Rada R. Comparison of different input selection algorithms in neuro-fuzzy modeling. Expert Systems with Applications. 2012;39:1536-44.

[22] Barak S, Dahooie JH, Tichý T. Wrapper ANFIS-ICA method to do stock market timing and feature selection on the basis of Japanese Candlestick. Expert Systems with Applications. 2015;42:9221-35.

[23] Ying L-C, Pan M-C. Using adaptive network based fuzzy inference system to forecast regional electricity loads. Energy Conversion and Management. 2008;49:205-11.

[24] Akdemir B, Çetinkaya N. Long-term load forecasting based on adaptive neural fuzzy inference system using real energy data. Energy Procedia. 2012;14:794-9.

[25] Al-Ghandoor A, Samhouri M, Al-Hinti I, Jaber J, Al-Rawashdeh M. Projection of future transport energy demand of Jordan using adaptive neuro-fuzzy technique. Energy. 2012;38:128-35.

[26] Azadeh A, Saberi M, Gitiforouz A, Saberi Z. A hybrid simulation-adaptive network based fuzzy inference system for improvement of electricity consumption estimation. Expert Systems with Applications. 2009;36:11108-17.

[27] $\mathrm{Li} \mathrm{K}, \mathrm{Su} \mathrm{H}$, Chu J. Forecasting building energy consumption using neural networks and hybrid neuro-fuzzy system: A comparative study. Energy and Buildings. 2011;43:2893-9.

[28] Li C, Hu J-W. A new ARIMA-based neuro-fuzzy approach and swarm intelligence for time series forecasting. Engineering Applications of Artificial Intelligence. 2012;25:295-308.

[29] Babu CN, Reddy BE. A Moving-Average-Filter-Based Hybrid ARIMA-ANN Model for Forecasting Time Series Data. Applied Soft Computing. 2014.

[30] Kavaklioglu K, Ceylan H, Ozturk HK, Canyurt OE. Modeling and prediction of Turkey's electricity consumption using artificial neural networks. Energy Conversion and Management. 2009;50:2719-27.

[31] Kucukali S, Baris K. Turkey's short-term gross annual electricity demand forecast by fuzzy logic approach. Energy Policy. 2010;38:2438-45.

[32] Chang P-C, Fan C-Y, Lin J-J. Monthly electricity demand forecasting based on a weighted evolving fuzzy neural network approach. International Journal of Electrical Power \& Energy Systems. 2011;33:17-27.

[33] Abraham A, Nath B. A neuro-fuzzy approach for modelling electricity demand in Victoria. Applied Soft Computing. 2001;1:127-38.

[34] Yan X, Chowdhury NA. Mid-term electricity market clearing price forecasting utilizing hybrid support vector machine and auto-regressive moving average with external input. International Journal of Electrical Power \& Energy Systems. 2014;63:64-70.

[35] Rahmani R, Yusof R, Seyedmahmoudian M, Mekhilef S. Hybrid technique of ant colony and particle swarm optimization for short term wind energy forecasting. Journal of Wind Engineering and Industrial Aerodynamics. 2013;123, Part A:163-70.

[36] Osório G, Matias J, Catalão J. Short-term wind power forecasting using adaptive neuro-fuzzy inference system combined with evolutionary particle swarm optimization, wavelet transform and mutual information. Renewable Energy. 2015;75:301-7.

[37] Hamzacebi C, Es HA. Forecasting the annual electricity consumption of Turkey using an optimized grey model. Energy. 2014;70:165-71.

[38] Xie N-m, Yuan C-q, Yang Y-j. Forecasting China's energy demand and self-sufficiency rate by grey forecasting model and Markov model. International Journal of Electrical Power \& Energy Systems. 2015;66:1-8.

[39] Azadeh A, Asadzadeh S, Mirseraji G, Saberi M. An emotional learning-neuro-fuzzy inference approach for optimum training and forecasting of gas consumption estimation models with cognitive data. Technological Forecasting and Social Change. 2015;91:47-63.

[40] Jovanović RŽ, Sretenović AA, Živković BD. Ensemble of various neural networks for prediction of heating energy consumption. Energy and Buildings. 2015;94:189-99.

[41] Kozak J, Boryczka U. Multiple Boosting in the Ant Colony Decision Forest meta-classifier. Knowledge-Based Systems. 2015;75:141-51.

[42] Haykin S. Neural networks: a comprehensive foundation, 1994. Mc Millan, New Jersey. 2010.

[43] Liu H, Tian H-q, Li Y-f, Zhang L. Comparison of four Adaboost algorithm based artificial neural networks in wind speed predictions. Energy Conversion and Management. 2015;92:67-81.

[44] Freund Y, Schapire RE. Experiments with a new boosting algorithm. In: Morgan K, editor. 13th International Conference on Machine Learning. San Francisco 1996. p. 148 - 56.

[45] Cao J, Kwong S, Wang R. A noise-detection based AdaBoost algorithm for mislabeled data. Pattern Recognition. 2012;45:4451-65.

[46] Nie Q, Jin L, Fei S. Probability estimation for multi-class classification using AdaBoost. Pattern Recognition. 2014;47:3931-40. 
[47] Assaad M, Boné R, Cardot H. A new boosting algorithm for improved time-series forecasting with recurrent neural networks. Information Fusion. 2008;9:41-55.

[48] Alfaro E, García N, Gámez M, Elizondo D. Bankruptcy forecasting: An empirical comparison of AdaBoost and neural networks. Decision Support Systems. 2008;45:110-22.

[49] Heo J, Yang JY. AdaBoost based bankruptcy forecasting of Korean construction companies. Applied Soft Computing. 2014;24:494-9.

[50] Pappas SS, Ekonomou L, Karampelas P, Karamousantas D, Katsikas S, Chatzarakis G, et al. Electricity demand load forecasting of the Hellenic power system using an ARMA model. Electric Power Systems Research. 2010;80:256-64.

[51] Ediger VŞ, Akar S. ARIMA forecasting of primary energy demand by fuel in Turkey. Energy Policy. 2007;35:1701-8.

[52] Lemaic M, Speckenmeyer E. Markov-Chain-Based Heuristics for the Minimum Feedback Vertex Set Problem.

[53] Sivanandam S, Sumathi S, Deepa S. Introduction to fuzzy logic using MATLAB: Springer; 2007.

[54] Xiong L. Data Mining: Concepts and Techniques.

[55] MéNdez GM, De Los Angeles HernáNdez M. Hybrid learning mechanism for interval A2-C1 type-2 non-singleton type-2 Takagi-Sugeno-Kang fuzzy logic systems. Information Sciences. 2013;220:149-69.

[56] Sadeghi M, Mirshojaeian Hosseini H. Energy supply planning in Iran by using fuzzy linear programming approach (regarding uncertainties of investment costs). Energy policy. 2006;34:993-1003.

[57] Geem ZW, Roper WE. Energy demand estimation of South Korea using artificial neural network. Energy Policy. 2009;37:4049-54.

[58] Kıran MS, Özceylan E, Gündüz M, Paksoy T. A novel hybrid approach based on particle swarm optimization and ant colony algorithm to forecast energy demand of Turkey. Energy conversion and management. 2012;53:75-83.

[59] Ünler A. Improvement of energy demand forecasts using swarm intelligence: The case of Turkey with projections to 2025. Energy Policy. 2008;36:1937-44.

[60] Barak S, Modarres M. Developing an approach to evaluate stocks by forecasting effective features with data mining methods. Expert Systems with Applications 2014.

[61] Babu CN, Reddy BE. A moving-average filter based hybrid ARIMA-ANN model for forecasting time series data. Applied Soft Computing. 2014;23:27-38.

[62] Khashei M, Bijari M. A novel hybridization of artificial neural networks and ARIMA models for time series forecasting. Applied Soft Computing. 2011;11:2664-75. 


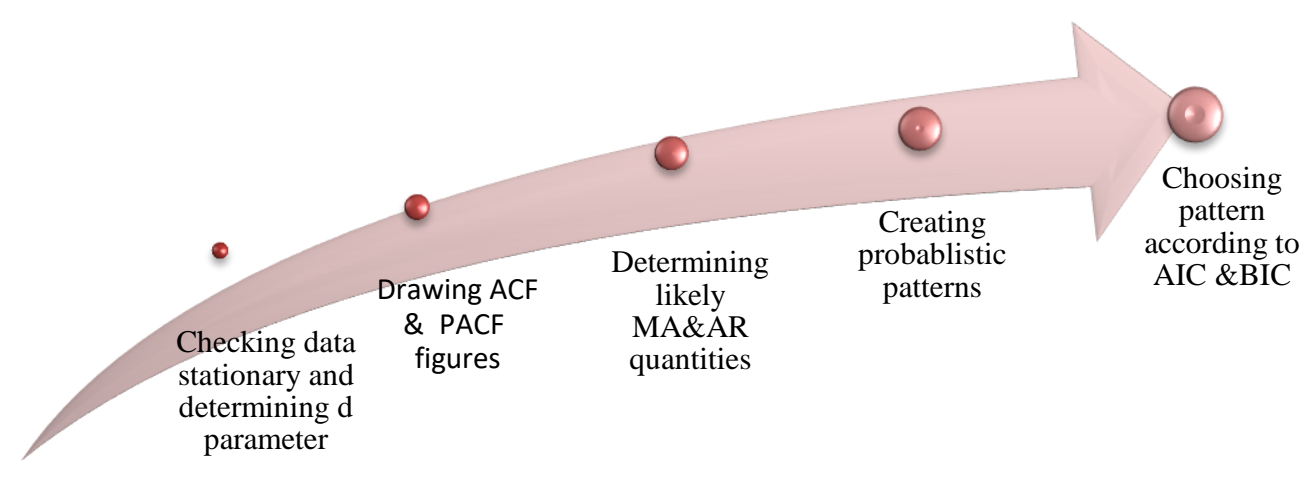

Figure1.Pattern of choosing the best ARIMA model

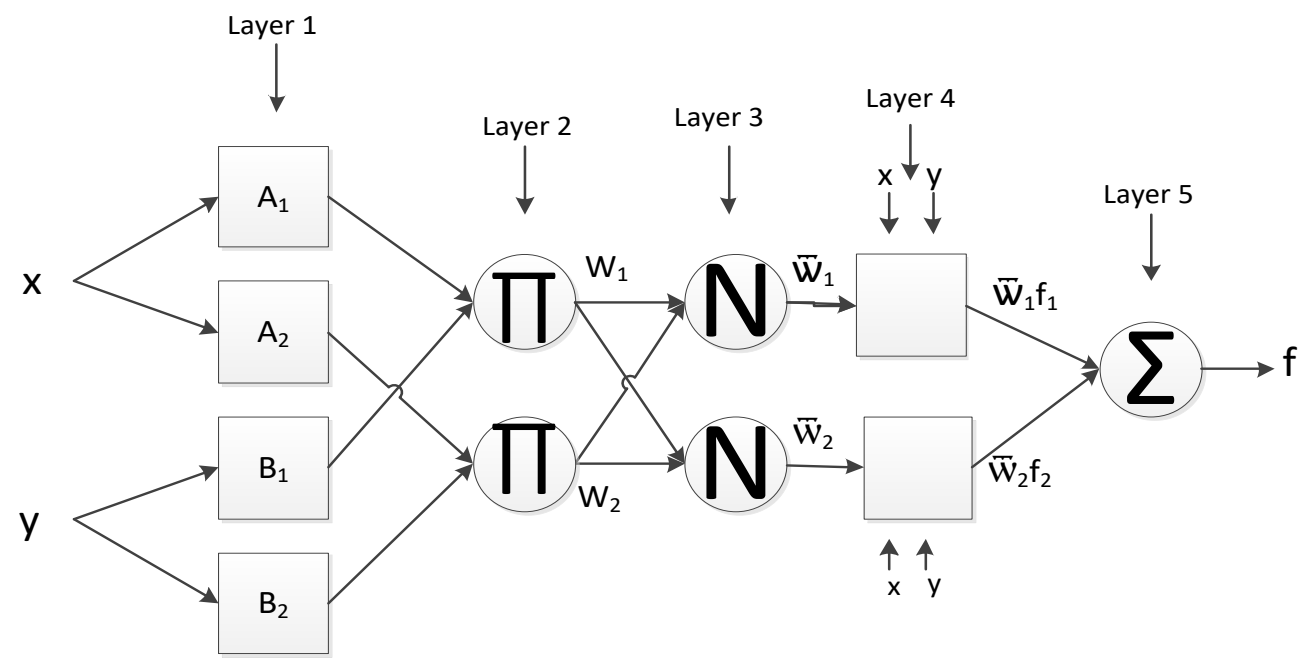

Figure2. ANFIS structure of type3, with 2 inputs and one output 


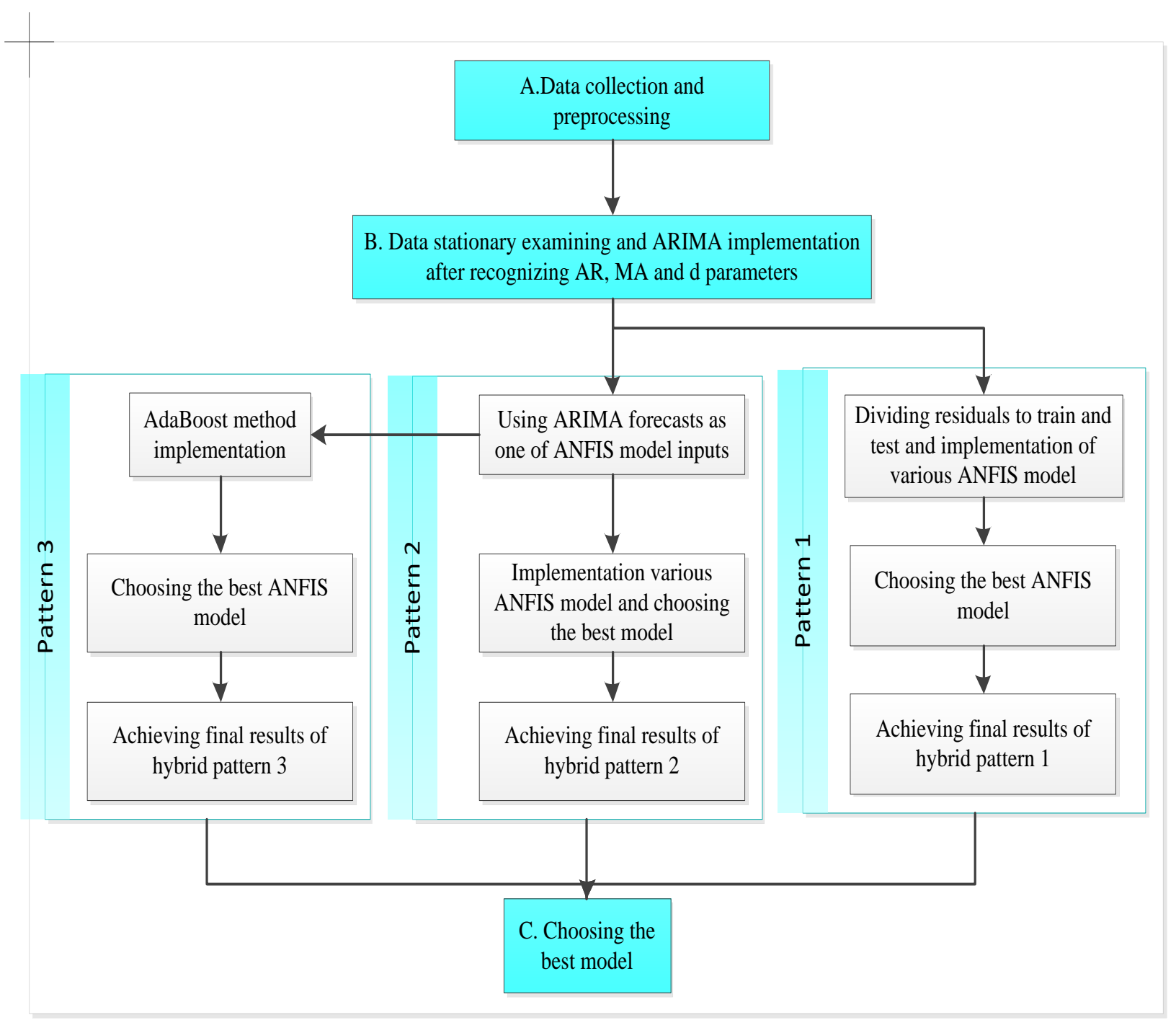

Figure3. Proposed hybrid ARIMA-ANFIS model 


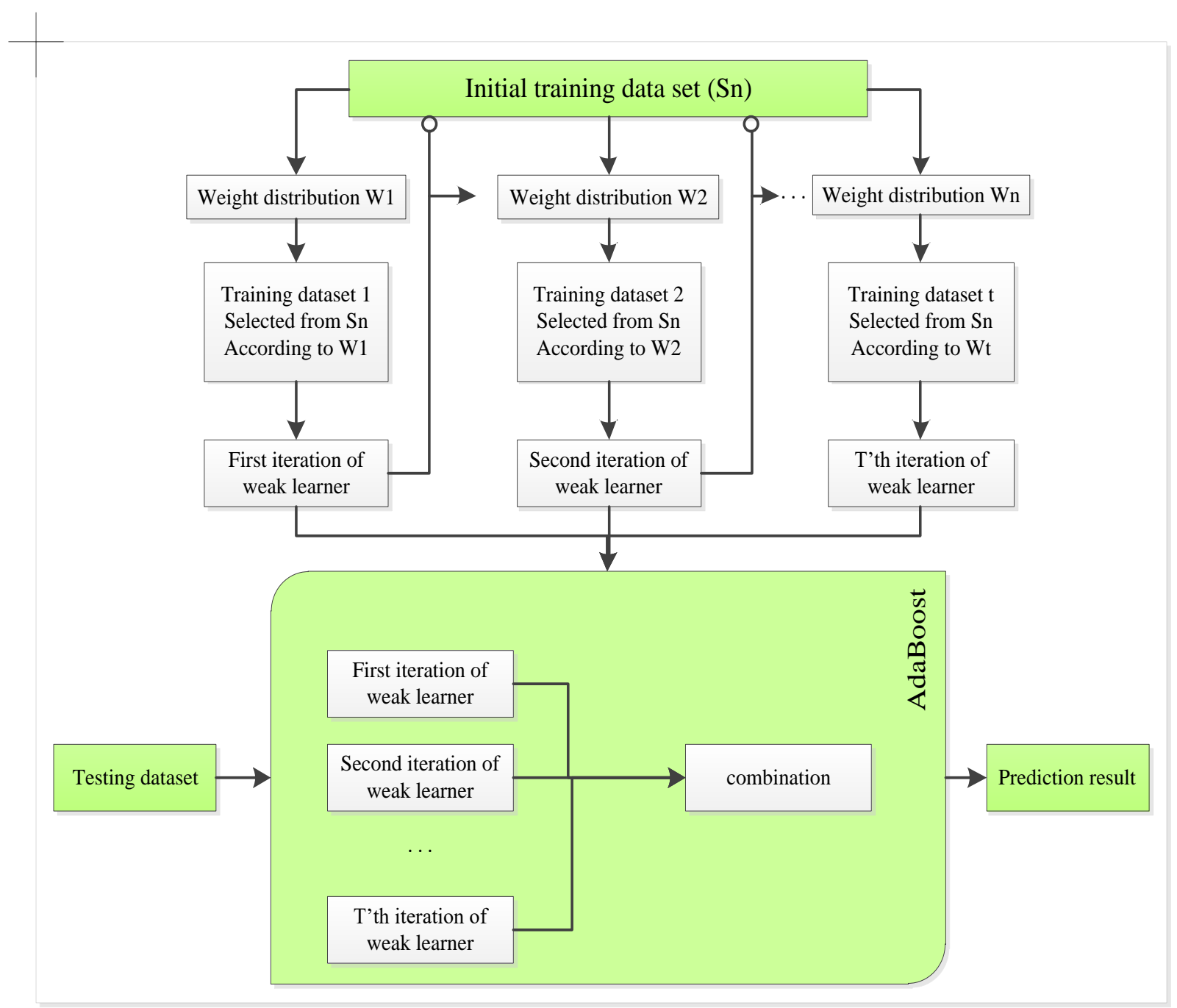

Figure4. Framework of AdaBoost method for predicting 


\begin{tabular}{|c|c|c|c|c|c|c|c|c|}
\hline \multicolumn{2}{|c|}{ Autocorrelation } & \multicolumn{2}{|c|}{ Partial Correlation } & & \multirow{2}{*}{$\begin{array}{l}\text { AC } \\
0.916\end{array}$} & \multirow{2}{*}{$\begin{array}{l}\text { PAC } \\
0.916\end{array}$} & \multirow{2}{*}{$\begin{array}{l}\text { Q-Stat } \\
38.659\end{array}$} & \multirow{2}{*}{$\begin{array}{l}\text { Prob } \\
0.000\end{array}$} \\
\hline 1 & & 1 & & 1 & & & & \\
\hline 1 & 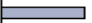 & & 1 & 2 & 0.833 & -0.040 & 71.380 & 0.000 \\
\hline 1 & & 1 & 1 & 3 & 0.744 & -0.081 & 98.125 & 0.000 \\
\hline & 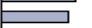 & 1 & I & 4 & 0.660 & -0.019 & 119.71 & 0.000 \\
\hline 1 & 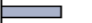 & 1 & 1 & 5 & 0.584 & 0.002 & 137.05 & 0.000 \\
\hline 1 & 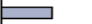 & 1 & 1 & 6 & 0.515 & -0.006 & 150.91 & 0.000 \\
\hline I & $\square$ & I & I & 7 & 0.452 & -0.011 & 161.89 & 0.000 \\
\hline 1 & 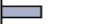 & 1 & 1 & 8 & 0.392 & -0.025 & 170.39 & 0.000 \\
\hline 1 & 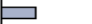 & 1 & 1 & 9 & 0.338 & -0.009 & 176.87 & 0.000 \\
\hline I & $\Xi$ & I & I & 10 & 0.283 & -0.038 & 181.58 & 0.000 \\
\hline I & יו & 1 & 1 & 11 & 0.233 & -0.019 & 184.85 & 0.000 \\
\hline i & 巨。 & i & i & 12 & 0.182 & -0.034 & 186.93 & 0.000 \\
\hline 1 & 巨。 & 1 & 1 & 13 & 0.129 & -0.060 & 188.01 & 0.000 \\
\hline I & & 1 & 1 & 14 & 0.076 & -0.047 & 188.40 & 0.000 \\
\hline i & i & i & i & 15 & 0.025 & -0.029 & 188.44 & 0.000 \\
\hline 1 & 1 & 1 & I & 16 & -0.025 & -0.048 & 188.49 & 0.000 \\
\hline 10 & 1 & I & 1 & 17 & -0.069 & -0.011 & 188.84 & 0.000 \\
\hline 10 & 1 & I & 1 & 18 & -0.108 & -0.019 & 189.74 & 0.000 \\
\hline 1 . & 1 & 1 & 1 & 19 & -0.139 & -0.009 & 191.30 & 0.000 \\
\hline 1 只 & $i$ & 1 & 1 & 20 & -0.169 & -0.034 & 193.71 & 0.000 \\
\hline
\end{tabular}

Figure5. Auto correlation and partial auto correlation in Iran`s data before lagging

\begin{tabular}{|c|c|c|c|c|c|c|c|c|}
\hline \multicolumn{2}{|c|}{ Autocorrelation } & \multicolumn{2}{|c|}{ Partial Correlation } & \multicolumn{2}{|r|}{$\mathrm{AC}$} & PAC & Q-Stat & Prob \\
\hline & 1 & 1 & 1 & 1 & -0.024 & -0.024 & 0.0244 & 0.876 \\
\hline I & I & 1 & 1 & 2 & -0.015 & -0.016 & 0.0347 & 0.983 \\
\hline & 1 & 1 & I & 3 & 0.057 & 0.056 & 0.1853 & 0.980 \\
\hline & 1 & 1 & I & 4 & 0.049 & 0.052 & 0.3015 & 0.990 \\
\hline 1 & 1 & 14 & 1 & 5 & -0.074 & -0.070 & 0.5675 & 0.989 \\
\hline I & I & 10 & I & 6 & 0.039 & 0.034 & 0.6437 & 0.996 \\
\hline I & I & I & I & 7 & 0.080 & 0.075 & 0.9778 & 0.995 \\
\hline I & 1 & I & I & 8 & -0.012 & -0.003 & 0.9858 & 0.998 \\
\hline 1 & 1 & 1 & I & 9 & 0.087 & 0.092 & 1.3987 & 0.998 \\
\hline & & & & 10 & 0.187 & 0.179 & 3.3925 & 0.971 \\
\hline 15 & I & 10 & 1 & 11 & -0.147 & -0.145 & 4.6666 & 0.946 \\
\hline & I & 1 & I & 12 & -0.002 & -0.003 & 4.6668 & 0.968 \\
\hline I & 1 & 1 & I & 13 & 0.112 & 0.086 & 5.4509 & 0.964 \\
\hline & I & 1 & 1 & 14 & -0.026 & -0.026 & 5.4953 & 0.978 \\
\hline $1 b$ & 1 & 1 b & 1 & 15 & 0.069 & 0.112 & 5.8220 & 0.983 \\
\hline 15 & I & 15 & I & 16 & -0.090 & -0.150 & 6.3974 & 0.983 \\
\hline 17 & I & 17 & I & 17 & 0.076 & 0.051 & 6.8212 & 0.986 \\
\hline 15 & 1 & 1 & I & 18 & -0.057 & -0.035 & 7.0708 & 0.990 \\
\hline 1 드 & 1 & 1마 & 1 & 19 & -0.156 & -0.227 & 9.0261 & 0.973 \\
\hline 1 & 1 & 11 & 1 & 20 & 0.001 & 0.013 & 9.0262 & 0.983 \\
\hline
\end{tabular}

Figure6. Auto correlation and partial auto correlation for $[1,1,2]$ model residuals 


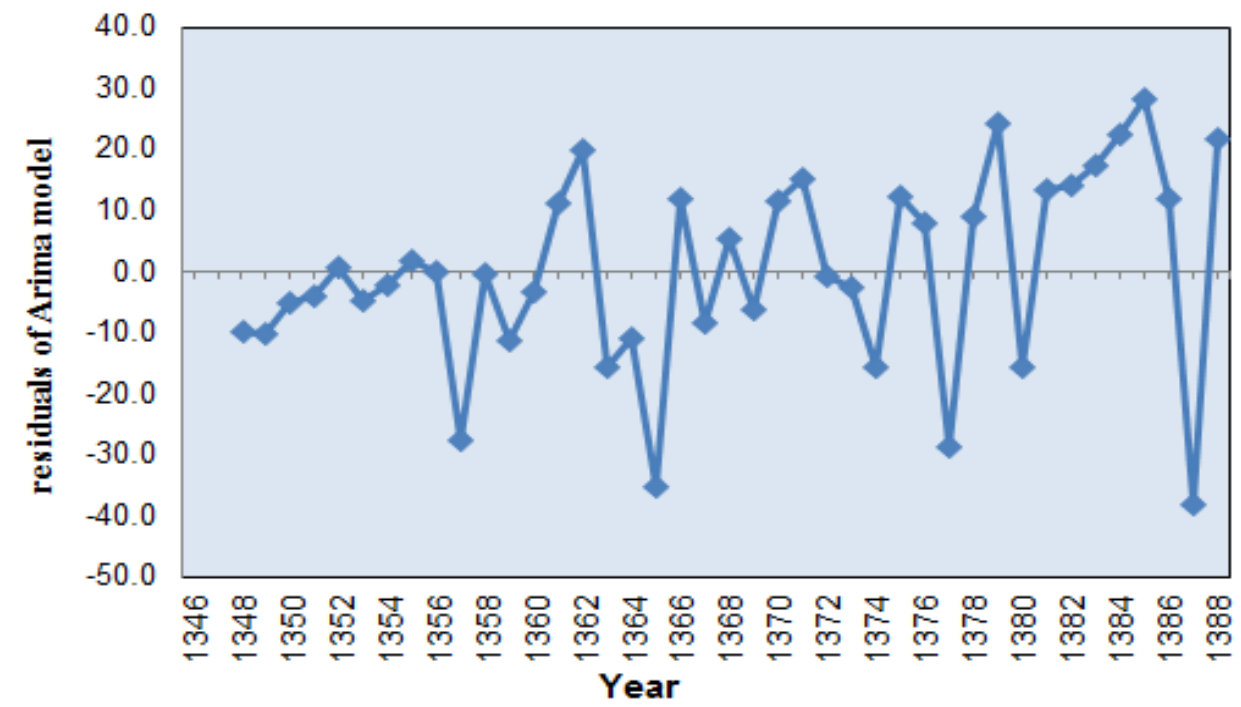

Figure7. ARIMA model forecasting residuals
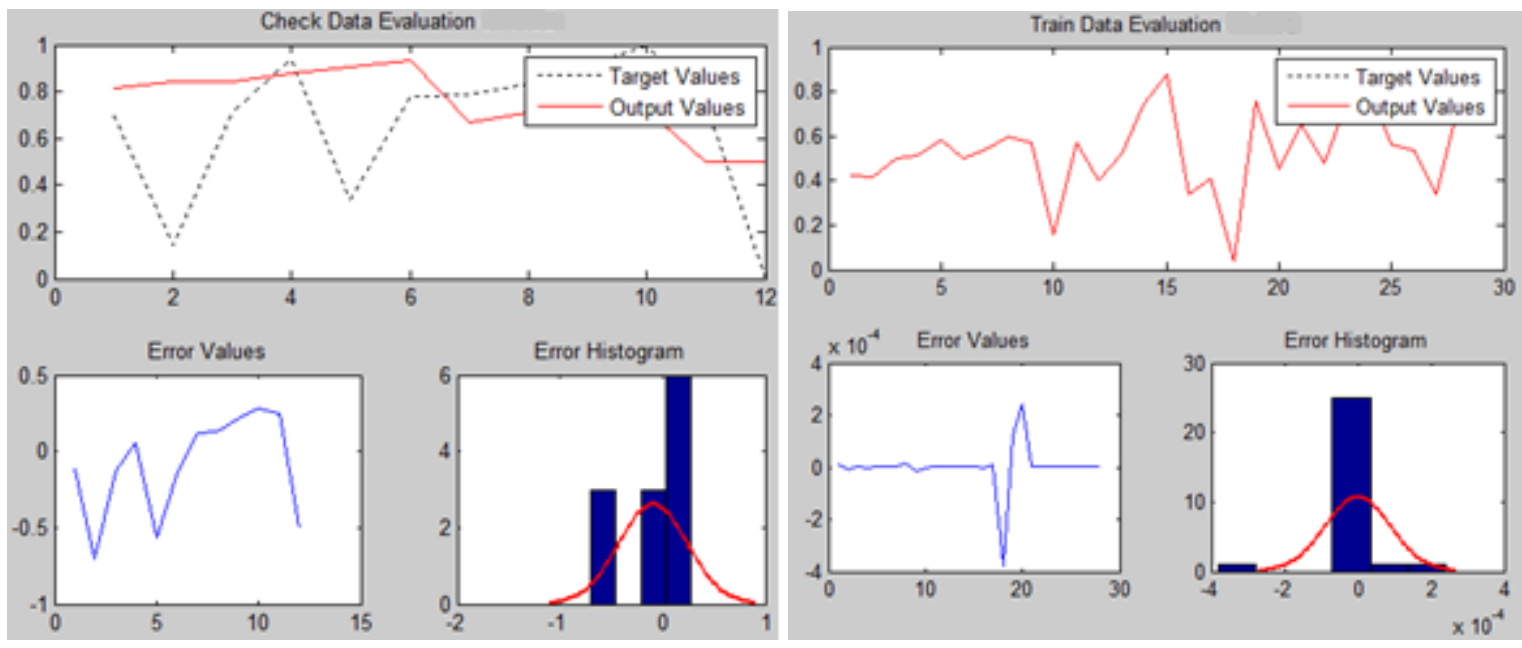

Figure8. Outputs and errors of hybrid pattern1, sub clustering type of ANFIS and hybrid BP training algorithm 

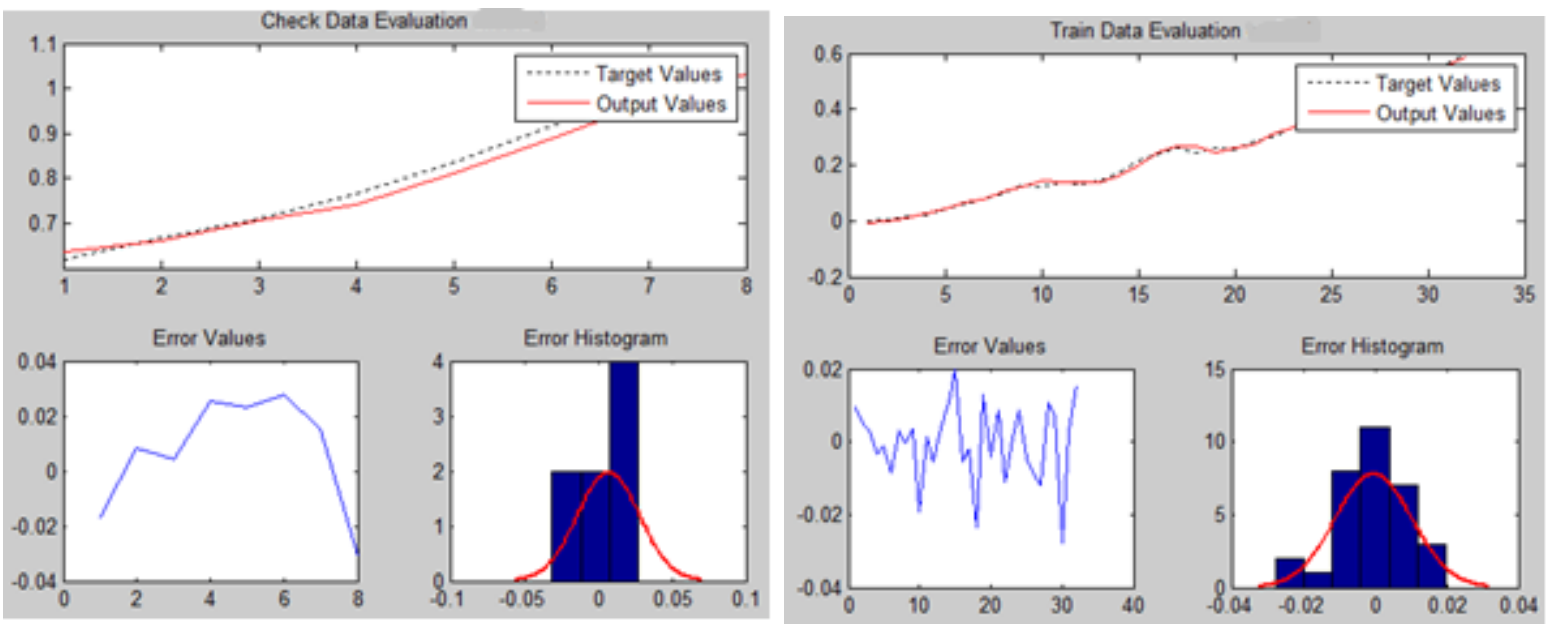

Figure9. Outputs and errors of hybrid pattern 2, FCM type of ANFIS and BP training algorithm 

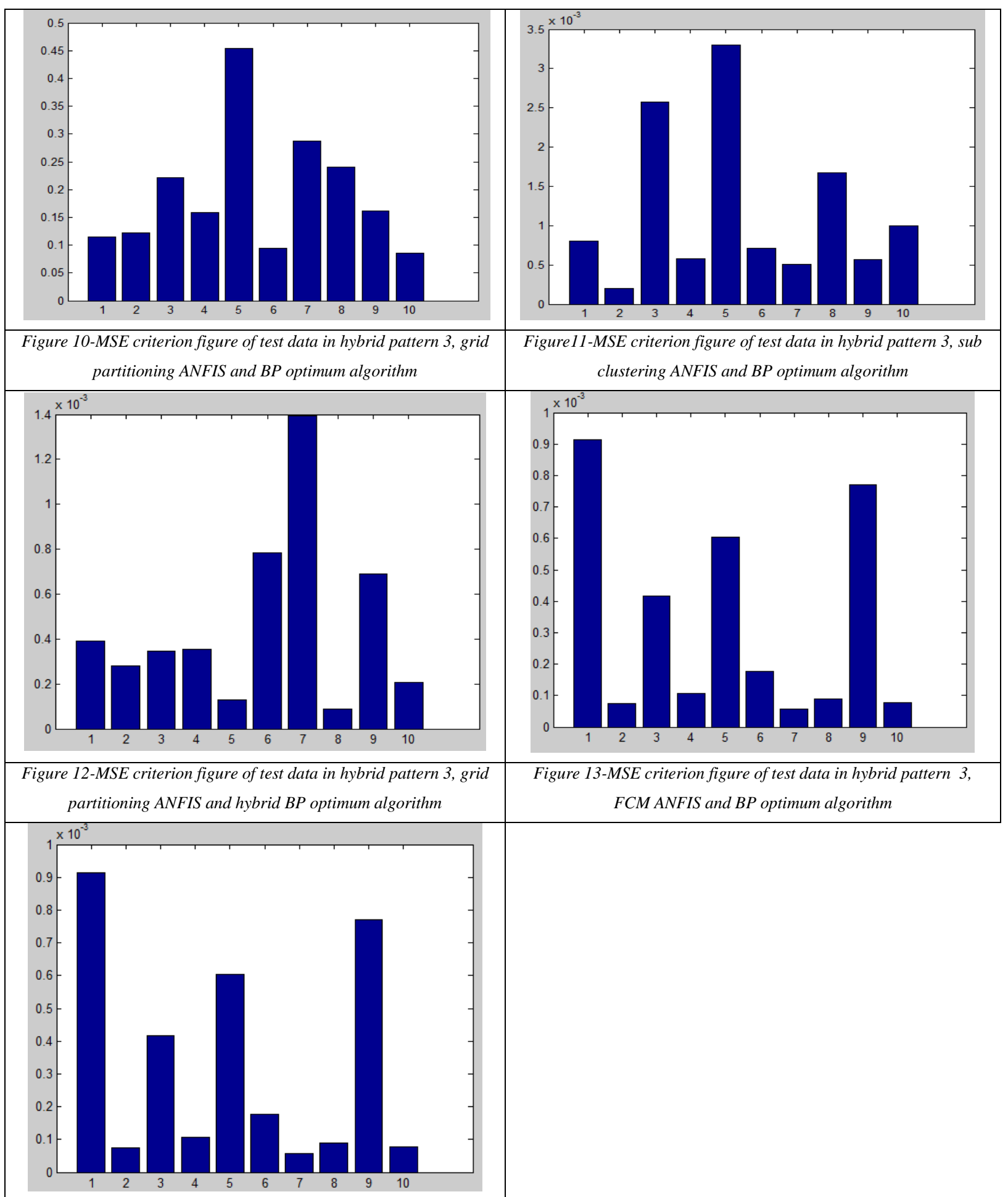

Figure 14-MSE criterion figure of test data in hybrid pattern 3, FCM ANFIS and hybrid BP optimum algorithm 


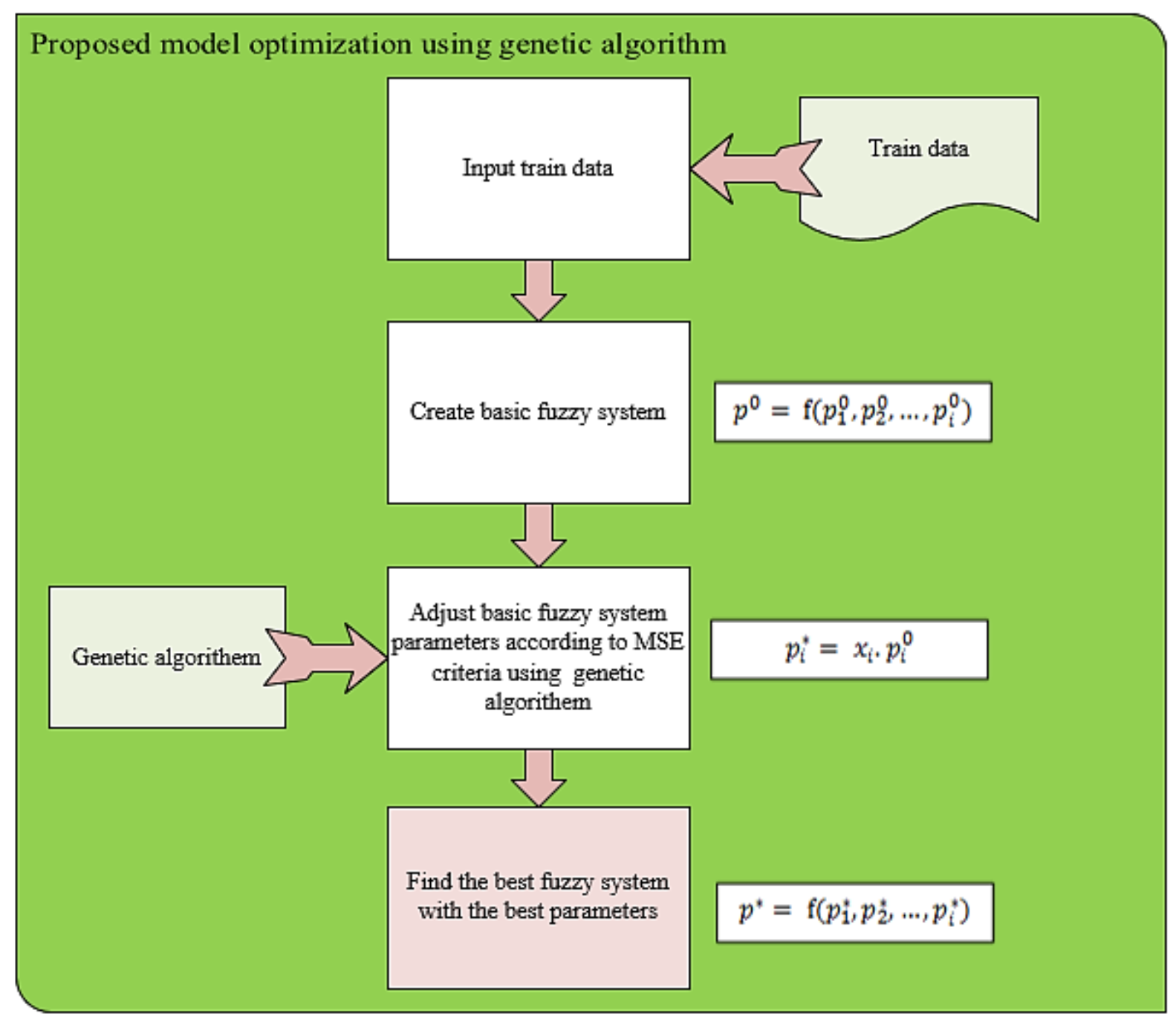

Figure15. ANFIS optimization using GA 
Table1. Review of hybrid energy forecasting implementations

\begin{tabular}{|c|c|c|c|c|c|c|}
\hline Number & Study & Study Field & Energy Market & Forecasting Method & Forecasting Scope & Error Percent \\
\hline 1 & [8] & Electricity & Greek & ARIMA & Daily & Best model: 1.4\% \\
\hline 2 & [13] & Electricity & Taiwan & $\begin{array}{c}\text { Neural network } \\
\text { Time series }\end{array}$ & Monthly & $\begin{array}{l}.02 \% \\
8.88 \%\end{array}$ \\
\hline 3 & [30] & Electricity & Turkey & Neural network & Annual & $1.15 \%$ \\
\hline 4 & [31] & Electricity & Turkey & Fuzzy logic & Annual & - \\
\hline 5 & [32] & Electricity & Taiwan & Weighted Neuro fuzzy & Monthly & $6.43 \%$ \\
\hline 6 & [14] & Electricity & A small region & Neuro Fuzzy & Annual & $17.62 \%$ \\
\hline 7 & [33] & Electricity & Australia & $\begin{array}{l}\text { ARIMA, Neural } \\
\text { network, Neuro fuzzy }\end{array}$ & 30 Minutes & $\begin{array}{c}\text { ARIMA:4.23\% } \\
\text { Neural network:3.23 } \\
\% \\
\text { Neuro fuzzy: } 0.92 \%\end{array}$ \\
\hline 8 & {$[10]$} & All kind of demand & $\begin{array}{l}3 \text { Company in } \\
\text { Istanbul }\end{array}$ & $\begin{array}{c}\text { Neuro fuzzy, Neural } \\
\text { network }\end{array}$ & Monthly & $\begin{array}{c}\text { Neuro fuzzy: } \mathbf{4 . 8 8 \%} \\
\mathbf{7 . 0 5 \%} \\
\mathbf{2 . 4 1 \%}\end{array}$ \\
\hline 10 & [25] & $\begin{array}{c}\text { Transportation } \\
\text { energy }\end{array}$ & Jordon & ANFIS & Annual & $0.155 \%$ \\
\hline 11 & {$[6]$} & Gas consumption & $\begin{array}{l}4 \text { Middle East } \\
\text { countries }\end{array}$ & ANFIS-SFA hybrid & Annual & $\begin{array}{c}\text { Bahrain:1.8\% } \\
\text { Saudi Arabia } \\
\text { :1.4\% } \\
\text { Syria:7.5\% } \\
\text { UAE:1.6\% }\end{array}$ \\
\hline 12 & [12] & Electricity & Iran & $\begin{array}{l}\text { ARIMA-fuzzy } \\
\text { regression }\end{array}$ & Monthly & $0.82 \%$ \\
\hline 13 & [34] & $\begin{array}{c}\text { Electricity market } \\
\text { clearing price } \\
(\mathrm{MCP})\end{array}$ & $\begin{array}{l}\text { PJM interconnected } \\
\text { electric market }\end{array}$ & $\begin{array}{c}\text { hybrid: } \\
\text { SVM- ARMAX }\end{array}$ & mid term & 0.144 \\
\hline 14 & [35] & wind energy & iran & $\begin{array}{c}\text { hybrid ant colony } \\
\text { (ACO) and particle } \\
\text { swarm (PSO) }\end{array}$ & short term (daily) & MAPE: $3.53 \%$ \\
\hline 15 & {$[36]$} & wind power & Portugal & ANFIS- EPSO & short term & MAPE: $3.75 \%$ \\
\hline 16 & [37] & electricity & Turkey & grey model & annual & MAPE: $\mathbf{3 . 2 8 \%}$ \\
\hline 17 & [38] & $\begin{array}{l}\text { energy production } \\
\text { and consumption }\end{array}$ & China & $\begin{array}{l}\text { Grey model- Markov } \\
\text { chain }\end{array}$ & annual & $\begin{array}{l}0.69 \% \\
0.93 \%\end{array}$ \\
\hline 18 & [39] & gas consumption & Iran & ELFIS- ANN- ANFIS & hourly & $\begin{array}{c}\text { ELFIS NMSE: } \\
0.26 \%\end{array}$ \\
\hline 19 & [40] & $\begin{array}{l}\text { heating energy } \\
\text { consumption }\end{array}$ & $\begin{array}{c}\text { Norwegian } \\
\text { University of } \\
\text { Science and } \\
\text { Technology building }\end{array}$ & $\begin{array}{c}\text { Ensemble of neural } \\
\text { networks }\end{array}$ & daily & MAPE: $5.25 \%$ \\
\hline
\end{tabular}


Table2. Akaike and Schwarz (BIC) criterions comparison for $[1,1,2]$ and $[2,1,1]$ ARIMA models

\begin{tabular}{ccc}
\hline model & {$[1,1,2]$} & {$[2,1,1]$} \\
\hline AIC & 8.497 & 8.5263 \\
BIC & 8.622 & $\mathbf{8 . 6 5 2 9}$ \\
\hline
\end{tabular}

Table3. Error criteria results of $[1,1,2]$ ARIMA model

\begin{tabular}{cc}
\hline model & {$[1,1,2]$} \\
\hline$R M S E$ & 15.7428 \\
$M A E$ & 12.5907 \\
\hline
\end{tabular}

Table4. MSE criterion results of test and train data in hybrid pattern 1

\begin{tabular}{cccc}
\hline MSE check data & Grid partitioning & Sub clustering & FCM \\
\hline BP & 0.461144459 & 0.129120718 & 0.2403921 \\
Hybrid BP & 0.37272772 & 0.111771157 & 0.1356161 \\
\hline & & & \\
\hline MSE train data & Grid partitioning & Sub clustering & FCM \\
\hline BP & 0.27423836 & 0.00157647 & 0.0261099 \\
Hybrid BP & $5.66 e-8$ & $7.87 e-9$ & $9.97 e-8$ \\
\hline
\end{tabular}

Table5. Train and test MSE criterion results of hybrid pattern 2

\begin{tabular}{cccc}
\hline MSE check data & Grid partitioning & Sub clustering & FCM \\
\hline BP & 0.670779481 & 0.111324451 & $5.76 e-4$ \\
Hybrid BP & 0.575888121 & 0.125924396 & 0.02944284 \\
\hline MSE train data & Grid partitioning & Sub clustering & FCM \\
\hline BP & 0.088080372 & $1.95 e-7$ & $1.43 e-4$ \\
Hybrid BP & $3.84 e-11$ & $4.4 e-12$ & $6.90 e-10$ \\
\hline
\end{tabular}


Table6. Fuzzy rules of ANFIs model of hybrid model 2

\begin{tabular}{|c|c|}
\hline 1 & $\begin{array}{c}\text { If (in1 is in 1cluster1) and (in2 is in2cluster1) and (in3 is in3cluster1) and (in4 is in4cluster1) and (in5 is in5cluster1) then (out1 is } \\
\text { out1cluster1) (1) }\end{array}$ \\
\hline 2 & $\begin{array}{c}\text { If (in1 is in 1cluster } 2) \text { and (in2 is in2cluster } 2) \text { and (in3 is in } 3 \text { cluster } 2) \text { and (in4 is in } 4 \text { cluster } 2) \text { and (in5 is in5cluster } 2) \text { then (out1 is } \\
\text { out1cluster } 2) \text { (1) }\end{array}$ \\
\hline 3 & $\begin{array}{c}\text { If (in1 is in1cluster3) and (in2 is in2cluster3) and (in3 is in3cluster3) and (in4 is in4cluster3) and (in5 is in5cluster3) then (out1 is } \\
\text { out1cluster3) (1) }\end{array}$ \\
\hline 4 & $\begin{array}{c}\text { If (in1 is in1cluster4) and (in2 is in2cluster4) and (in3 is in3cluster4) and (in4 is in4cluster4) and (in5 is in5cluster4) then (out1 is } \\
\text { out1cluster4) (1) }\end{array}$ \\
\hline 5 & $\begin{array}{c}\text { If (in1 is in1cluster5) and (in2 is in2cluster5) and (in3 is in } 3 \text { cluster5) and (in4 is in4cluster5) and (in5 is in5cluster5) then (out1 is } \\
\text { out1cluster5) (1) }\end{array}$ \\
\hline 6 & $\begin{array}{c}\text { If (in1 is in1cluster6) and (in2 is in2cluster6) and (in3 is in3cluster6) and (in4 is in4cluster6) and (in5 is in5cluster6) then (out1 is } \\
\text { out1cluster6) (1) }\end{array}$ \\
\hline 7 & $\begin{array}{c}\text { If (in1 is in1cluster7) and (in2 is in2cluster7) and (in3 is in3cluster7) and (in4 is in4cluster7) and (in5 is in5cluster7) then (out1 is } \\
\text { out1cluster7) (1) }\end{array}$ \\
\hline 8 & $\begin{array}{c}\text { If (in1 is in 1cluster8) and (in2 is in2cluster8) and (in3 is in } 3 \text { cluster8) and (in4 is in } 4 \text { cluster8) and (in5 is in5cluster8) then (out1 is } \\
\text { out1cluster8) (1) }\end{array}$ \\
\hline
\end{tabular}

Table7. Test and train MSE criterion of hybrid model 3

\begin{tabular}{cccc}
\hline MSE check data & Grid partitioning & Sub clustering & FCM \\
\hline BP & 0.193931541 & $1.19 e-3$ & $2.63 e-4$ \\
Hybrid BP & 0.080798813 & $4.66 e-4$ & $3.29 e-4$ \\
\hline \multicolumn{4}{|c}{} \\
\hline MSE train data & Grid partitioning & Sub clustering & FCM \\
\hline BP & 0.189186074 & $4.45 e-7$ & $1.37 e-4$ \\
\hline Hybrid BP & $1.74 e-11$ & $3.46 e-12$ & $4.76 e-7$ \\
\hline
\end{tabular}


Table8. Results of the best practice of hybrid pattern 1, 2 and 3

\begin{tabular}{rccc}
\hline MSE criterion & Hybrid pattern 1 & Hybrid pattern 2 & Hybrid pattern 3 \\
\hline Test data & 0.111771157 & $5.76 e-4$ & $2.63 e-4$ \\
Train data & $7.87 e-9$ & $1.43 e-4$ & $1.37 e-4$ \\
\hline
\end{tabular}

Table9. Comparison results

\begin{tabular}{|c|c|c|c|c|c|c|c|c|c|}
\hline $\begin{array}{c}\text { MSE } \\
\text { criterion }\end{array}$ & $\begin{array}{c}\text { single } \\
\text { ARIMA }\end{array}$ & $\begin{array}{c}\text { single } \\
\text { ANFIS }\end{array}$ & ANN & $\begin{array}{c}\text { Zhang } \\
\text { [7] }\end{array}$ & $\begin{array}{c}\text { Khashei and } \\
\text { Bijari [62] }\end{array}$ & $\begin{array}{c}\text { Babu and } \\
\text { Reddy } \\
{[29]}\end{array}$ & $\begin{array}{c}\text { hybrid } \\
\text { pattern 1 }\end{array}$ & $\begin{array}{c}\text { hybrid } \\
\text { pattern 2 }\end{array}$ & $\begin{array}{c}\text { hybrid } \\
\text { pattern 3 }\end{array}$ \\
\hline test data & 3.97 & 0.121771 & 0.155 & 0.1431 & 0.0833 & 0.0266 & 0.1117712 & $5.76 \mathrm{e}-4$ & $2.63 \mathrm{e}-4$ \\
\hline train data & - & $7.97 \mathrm{E}-09$ & 0.176 & 0.041 & 0.009 & 0.0073 & $7.87 \mathrm{e}-9$ & $1.43 \mathrm{e}-4$ & $1.37 \mathrm{e}-4$ \\
\hline
\end{tabular}

Table10. Results of optimized ANFIS using GA and PSO

\begin{tabular}{|l|r|r|r|r|r|r|}
\hline \multicolumn{1}{c|}{ Test Result } & 1 & 2 & 3 & 4 & 5 & average \\
\hline MSE ANFIS PSO & 0.00021 & $6.02 \mathrm{E}-05$ & 0.0006893 & 0.00035 & 0.00044 & 0.00035 \\
\hline RMSE ANFIS PSO & 0.01447 & 0.00776 & 0.0262536 & 0.01876 & 0.02105 & 0.01766 \\
\hline MSE ANFIS GA & 0.00053 & 0.00019 & 0.0002733 & 0.00025 & 0.00025 & 0.0003 \\
\hline RMSE ANFIS GA & 0.02308 & 0.01379 & 0.0165311 & 0.01577 & 0.0157 & 0.01697 \\
\hline
\end{tabular}

